\title{
La Necesidad For More Latina Superintendents! : An Autoethnographic Account of a Latina Navigating to the Superintendency (Dale, Dale, Dale! A.k.a., The Mexican Piñata song)
}

\author{
Dr. Christina Luna, Ed.D., California State University, Fresno
}

DOI: $10.36851 / j t / p s . v 9 i 1.2270$

Women in educational leadership positions have to break a glass ceiling to get to the top despite their dominance in the teaching profession and as California educators. Latinas (Latinx women) ${ }^{1}$ however face far greater challenges, not only does sexism present challenges but so does racism (see Campbell-Jones \& Avelar-Lasalle, 2000). The tenacity, strategies and fortitude are more akin to breaking a piñata, much more challenging and with a greater risk than a glass ceiling. Educational attainment, career support, gender and cultural bias all factor into some of the many challenges Latinas face as they aspire to higher levels of educational administration positions. The challenge for Latinas can be greater than for others, however, the journey and lasting effects are worth it, just as the treats that flow from a well-broken piñata, the rewards of holding the position of Superintendent are significant for those that aspire to and accomplish the goal, and are celebrated by those who assist and participate in their efforts.

This autoethnographic study focuses on the Superintendency from a Latina perspective. The study presents specific insights and lessons learned that can assist Latinas and people of color who are high-level ${ }^{2}$ and district administrators or those who aspire to the superintendency. There are 1,037 school districts in California (CalEdFacts, 2019), thus the information and lessons learned from my experience may also characterize the superintendency and/or high-level administrative positions. The importance of my experience rests in the fact that while the total number of Latinx administrators comprises approximately only $23 \%$ of site and district administrators in California as compared to the majority who are White and comprise approximately 59\% (CDE/DataQuest, 2019), equity scholars would find this problematic given that the overwhelming majority of students in PK-12 schools are Latinx.

\section{Demographic Context of Latinx Underrepresentation in California's Leadership}

California demographics for the 2018/19 school year indicate Latinx children comprise 55\% of the total PK-12 schoolage population, followed by $23 \%$ Whites and $9 \%$ Asians (California Department of Education, 2018). Educational systems, per se, remains a female-dominated profession that is characterized by male-dominated leadership (Muñoz, Pankake, Ramalho, Mills, \& Simonsson, 2014). Aspirations of becoming a superintendent are often secondary or not even mentioned on the goal attainment list for Latinas as they often struggle just to become professional educators. Latinas are making gains in the teaching profession; however, they remain at lower levels of attaining higher edu1 Latinx refers to both male and female persons of Latino descent. Latinas refer to women only and Latinos refers to men only.

$2 \quad$ High-level administrators include principals and district office directors and assistant superintendents. 
cation, including doctorate degree attainment, which often limits their marketing qualifications and opportunities for superintendent level positions. The California Department of Education indicated 63,380 (20\%) of teachers were Hispanic compared to 190,012 (62\%) who identified as White during the 2017/18 school year (CalEdFacts, 2019).

The same time-period indicated 6,042 (20\%) Hispanics were administrators compared to 16,016 or approximately $60 \%$ who identified as whites (California Department of Education Data Quest Staff by Ethnicity, 2018). The number of superintendents for the $2017 / 18$ school year was 920 of which 384 were women, of those women superintendents only 37 self-identified as Latinas (Cano, 2019). The numbers are important when we consider the number of Latinx students in California's schools comprise $55 \%$ of the total student population followed by whites at $23 \%$ and Asians at $9 \%$.

\section{Theoretical Framework}

The most closely related theoretical framework that is addressed in this study is The Conceptual Framework for Culturally Proficient Practices. The tenets of the framework are designed to foster culturally proficient practices regarding; assessing one's cultural knowledge; valuing diversity; managing the dynamic of difference; adapting to diversity and institutionalizing cultural knowledge (Lindsey \& Lindsey, 2016). It is the Cultural Proficiency Framework that most closely addresses the varied and simultaneous challenges and barriers Latina superintendents and those that recruit and hire them must address to attain leverage and success.

Traditional theoretical frameworks such as those contextualizing challenges of race, gender, educational attainment, and financial status are too limiting to explain the Latina superintendency. The phenomena of the Latina superintendency simultaneously typify and exemplifies both inter and intra; racial stereotypes; gender stereotypes; educational stereotypes, and limited majority-based cultural capital. These characteristics create a challenge for identifying a traditional critical framework such as critical race theory, that do not adequately address the multiple hurdles for Latina leaders.

\section{Methodology}

The methodology for this article is autoethnography (Denzin \& Lincoln, 2011). The value of autoethnography is that it presents experiences and ideas that can be learned from such as those presented in case studies and action research. Méndez (2013) indicated autoethnography can be used by the researcher to draw upon their own experiences to understand a particular phenomenon or culture. Méndez (2013) also stated, "through reading a cultural or social account of an experience, some may become aware of the realities that may not have been thought of before." (p.282). The autoethnographic approach is most appropriate given the limited number of Latina superintendents who are both a phenomenon and the superintendency which is a culture in and of itself. In using the autoethnographic approach, the desired result is that the reader becomes educated to the barriers, resistance and contributing factors for female high-level administrators' success. The author was a teacher and administrator in Los Angeles and Orange counties and a Superintendent in Tulare and Imperial counties in California. Hoff, Menard and Tuell (2006) suggested that women believe they need to travel the conventional path of teacher, to principal, to assistant superintendent, coupled with a doctorate to attain the position of superintendent. The author of this study definitely traveled this path, from instructional assistant, to teacher, to vice principal, to coordinator, to director, to assistant superintendent, to superintendent while attaining a clear administrative credential and a doctorate. The author is of Mexican descent and was blessed with brown skin, brown hair, and brown eyes. 
Complimenting the autoethnography approach the paper is grounded in the educational benefits of action research. Whitehead and Lomax (1987) refer to action research as a process that is formative rather than summative and "exemplifies the nature of the educational world as experienced and negotiated by practitioners within it" (pg. 176). The author intends to provide perspective and offer advice to future Latinx administrators and to those who are in hiring positions, using data, research and by sharing events and experiences from actual educational situations. As previously mentioned, the Latina experience and the superintendency are comprised of unique attributes not often found in the literature, sharing the lived experiences is an attempt to add to the scholarly literature regarding the Latinx cultura (culture) and addressing administrative challenges.

This autoethnographic study personifies the author's journey and experience as being the first and only Latina administrator in differing districts and her role as superintendent. Illustrated are the challenges, learning experiences, and words of encouragement beneficial for aspiring higher-level administrators including the superintendency and the Latinx educator population in general. The experience of the author notes the challenges faced by women entering the male-dominated field of school administration and the ascendency to higher levels of administration including the superintendency. Highlighted are the compounding challenges for women in general such as mobility, male-dominated institutions and gender expectations. The challenges faced by women overall are often exacerbated for Latinas. Challenges such as; perceived Latina gender roles, expectations and the influence that cultural stereotypes have on the non-traditional female leadership role of being the superintendent are discussed from lived experiences.

Latinas are an important part of the Latinx family fabric, their place in the family structure and community can be a positive influence for Latinx children. Latina administrators visible to school children can provide inspiration and serve as role models to the many Latinx children who aspire to graduate from high school and attain college degrees, resulting in future educational Latinx leaders. The experience of being an agent of change and having a voice is shared and reflected upon by the author as she shares her journey of using the attributes of Latinx cultural capital in educational and administrative attainment. The cultural aspects of role models, mentors and familia (the nuclear and nonnuclear family) are recognized as strengths in gaining, providing and challenging the system.

\section{THE JOURNEY}

\section{Latinx Students and Administrators}

Education per se is a female-dominated profession regarding the number of educators, however, regarding administrators males overwhelming outnumber females. According to Muñoz, Pankake, Ramalho, Mills, \& Simonsson (2014), only $24.1 \%$ of the nation's superintendents are female and their numbers are not increasing at substantial rates. Their research suggested at the present rate of progress it will take over 30 years for women to achieve equitable numbers in the superintendency. The nation's largest Latinx student population resides in California where over 55\% of the total school-age population is Latinx compared to whites who represent a little more than $23 \%$ of the school-age population. (California Department of Education, 2018). In the 2018 school year, female teachers in California outnumbered males and comprised $73 \%$ of the teaching professionals, of those females only $20 \%$ were identified as Latina. There were 90,410 principals leading California schools represented by $54.2 \%$ women of which less than $1 \%$ were Latina. There were 920 superintendents in California and a little more than $41 \%$ were females, disappointingly less than .04\% or 37 self-identified as Latina. (Cano, 2019).

In a recent EdSource article by Lambert (2019) she indicated the current State Superintendent of Public Instruction, Thurmond, has made it a priority to increase the number of teachers of color in California's classrooms. Thurmond 
(2019) was quoted in an EdSource interview as saying, ["the data shows when kids see a teacher who looks like them it makes a huge difference"] (p. 1). In the recent Learning Policy Institute Brief (2019) a finding indicated, California principals lack learning that supports students from diverse ethnic, racial, linguistic, and cultural backgrounds (Sutcher, Podolsky, Kini, \& Shields, 2018). It is a well-accepted concept that improving student achievement requires prepared teachers, administrators and as the current research illustrates administrators who share cultural, linguistic and ethnic identities akin to the student population. The research study, Some Key Issues in Teaching Latino Students, Moll (1988, p. 469-470) found that teachers who provide lessons that are linked to students' social experiences in the home and community result in increased achievement outcomes for students.

As a Latina principal in a Latinx community where I grew up, we accomplished great academic gains and I had positive community support. As a high-level administrator, I mistakenly thought being bilingual and bicultural would assist in my success; however, my experiences taught me, there is a continuing need to learn the specifics about the children and communities we serve. As an assistant superintendent, I was the only Latina administrator in the district. It did help to understand the struggles of the recent arrival Asian students and their families however there was a learning curve regarding the ethnic and economic base of the students and many of the faculty members who were majority white.

In my experiences as superintendent, I looked very similar to the student and family populations where I worked. However, the cultural community nuances were very different. As superintendent, I was a suburbanite in rural communities. In research conducted by Hollins (2012) she found that teachers who understand and apply the lived experiences of children in teaching are more successful than those who do not. Hollins (2012) contended that when working with children asset-based thinking and practices are a must when considering academic outcomes (Hollins, 2012). My position is, that educators are those that are continually learning and growing in order to meet the needs of the children they work with. With that being said much of the research on teacher success can be applied to administrative success. As educators, it is important to continue to learn to how best meet the needs of our students and to consciously implement those strategies. In the case of high-level and elite ${ }^{3}$ administrators it is important to also learn about their community's unique cultures.

\section{My First Mentor and Comadre 4}

I began my career as a middle school teacher at a year-round school. When I was off track, I volunteered in my daughter's kindergarten classroom. The principal of the school was a beautiful Latina who wore flowing dresses in bright colors, she was one of the first Latina administrators I had ever seen. It was obvious she loved what she did, I can remember her signing to the deaf and hard of hearing class as they passed her in the hallways. One day I asked when she learned to sign and she replied when she agreed to have the deaf and hard of hearing program at the school. She explained it was important to communicate with the children in our care and with their parents. She was bilingual English/Spanish, but that was not enough she learned to sign in order to better serve her students and their families.

Several years later I was fortunate to become a principal in the district where she became a district office administrator and later an Assistant Superintendent. She hugged me and congratulated me when I became a principal and soon after would refer to me as comadre. She took me under her wing, mentored me, wiped my tears and was always

$3 \quad$ Elite administrator refers to the superintendency

$4 \quad$ Comadre in English is translated as the Godmother of one's child. Balderama and Rodriguez (2006) refer to comadres (female) (compadre-male) as the extended family, not necessarily blood relatives, but people who are close to someone and who are a protective source. 
there for me. It has been over 30 years since we first met, and I have gone on to different districts and positions. To this day we still talk and meet for lunch, when I call, I am always greeted by, "Hello Comadre”.

In the book, Decade of Betrayal, Baldaram and Rodriguez (2006) best explain the importance of La Familia, (the family) in Mexican communities. Citing the family was a link to the past and a step forward to the future. "It embodied not only acculturation and change but stability as well. La familia was a protective source consisting of the extended family. Mexican immigrants had an invisible network informally maintained by las comadres, to keep in touch with relatives and friends"(pg. 38-39) The concept of comadras $\mathrm{CO}^{5}$ or in the case of this study compadrasco, to include not only women but men is an important cultural attribute that assisted me in maintaining strength, a positive ethnic identity and a source of familiar and similar mentors.

Mentors are mentioned throughout the literature as a necessary element for successfully attaining administrative positions (MacArthur, 2010). The challenge for females is that mentors are not as readily available as they are for men (Brunner, 2018) due to fewer mentoring opportunities and because there just aren't many role models. When we look at the number of females in administrative positions these numbers clearly indicate a lack of role models and mentors. The challenge for Latinas is the number is even less, if not nonexistent.

As an aspiring high-level and elite administrator, the author often sought advice, mentoring and assistance from those that she considered to be comadres and compadres. This form of mentoring and care is different in that the cultural nuances of the Latinx community are considered. The author refers to Latinx mentoring as comadrasco or compadrasco. As Baldarama stated, a connection to the cultural past and support for moving forward. This concept is important for Latinas as we not only recognize but celebrate our differences than the norm in attaining and maintaining high-level and elite administration positions. When I felt out of place and needed a mentor being greeted with, "comadre, how are you" provided an instant effect of comfort and familiarity.

\section{Ascendency to the Superintendency and Becoming a Role Model}

My experience as an administrator can be described as one of firsts. I began my administrative career as a vice-principal and quickly moved to district office administration due to my background in science and staff development. I became a State and Federal project director where my responsibilities included writing grants, managing budgets and implementing staff and parent empowerment programs. The early experience of fiscally managing millions of dollars and being responsible for multiple educational programs served me well throughout my entire career. As a new administrator, I would take on extra tasks such as grant writing, creating programs and attending training workshops at the county, state and federal levels. I was enjoying the challenges and learning experiences and it did not occur to me, I had entered a male-dominated field. Skrla (2001) stated, female applicants often face misperceptions regarding their leadership abilities in regard to non-academic areas such as facilities, athletics and budgets. This may be true, due to a lack of being offered or included in opportunities to learn and to have hands-on experience. Taking advantage of workshops and training opportunities and volunteering were important to developing needed skills. My early years in administration and my eagerness to learn prepared me well for the superintendency. I was well equipped and had a solid understanding and working knowledge of facilities, budgets and later with athletics.

$5 \quad$ Comadrasco (female) compadrasco (male) refers to comadres /compadres helping a comadre 
In the early 2000s, I was hired as an assistant superintendent in a southern California school district. I was the first and only Latinx administrator in the district, there were no site or district administrators of Latino descent prior to my tenure in the district. I would often think it's 2009 and this district has never had a Latina administrator? I can recall attending events and district-sponsored meetings where parents, students and the community were in the audience, and I could hear people whispering, "look she's a Latina." Most often the comments were from Latino couples, I would acknowledge them with a smile and a nod, and they would smile back. I did not view these acknowledgments as negatives but rather as a positive affirmation, that I belonged there just like everyone else. And that perhaps I was a role model for the students and the community.

As a district office administrator and later as a superintendent, it was customary for us to dress in our university regalia and sit on the stage during the high school's commencement. My regalia often stood out as I proudly displayed my alma mater's red doctorate gown. A couple of years following my superintendency I was at a university gathering and a young lady approached me and said, "Hello Dr. Luna." I did not recognize her, and she must have noticed my expression, because she quickly said, "you don't know me, but I know you. I saw you at my sister's graduation and I remember telling my parents, wow, look at her a Latina superintendent and she has a doctorate from USC, she told her parents that would be her one day." I remember the conversation and the pride she had on her face when she told me she was in her third year at the university and would be graduating and then going on to get her master's and doctorate. I gave her a hug and told her she could do it! It is moments like this that should remind us of the importance we have in our communities and to our Latinx children and families. We are role models and we may not even know to whom.

As a superintendent, I was always conscious that I represented more than myself and was always on public display. I did not realize how others viewed this until in one of our administrative meetings the Assistant Superintendent of human resources was making a presentation regarding the importance of positive perception and how principals need to be positive role models for our students and the community. As she was presenting, she told the administrative team, "when we go to lunch with the superintendent, she asks to not be seated in the bar area of the restaurant. The superintendent is aware of how the community views us and it is our responsibility to be mindful of our responsibility to our students and the community. At the conclusion of the meeting, I realized I was not only a role model for the students and community but for the administrative staff as well.

\section{Mentors, Challenges, and Cultural Capital}

In the article, A study of female central office administrators and their aspirations to the superintendency (2014) the researchers described the position of the superintendent as a revolving door with terms of employment lasting two to three years on average. The researchers stated, "Men consider a term of two to three years as a major win and move on to obtain other superintendent positions, while women may not or will not seek other superintendent roles with the same ease and tenacity." And that women often view a two to three-year tenure as a negative and find it a daunting task to reapply elsewhere (Muñoz, Pankake, Ramalho, Mills, \& Simonsson, 2014). The revolving door reality of the superintendency was an unwelcome challenge and created feelings of failure and insecurity for me. Knowing the realities and seeing males, both white and those of color leaving their positions did not do much to quell my insecurities and I questioned my abilities as a superintendent. Upon reflecting on the revolving door reality, I can remember a friendly conversation from a white male colleague who explained the tenure of the superintendency as not being a two to three-year contract but being a two to four-week position, depending on how often the Board meets, it became an inside joke and when we would see each other over the course of two years, we would greet 
each other with "still here". I was fortunate to work with supportive male superintendent colleagues and some who I considered friends and mentors. The findings of Muñoz, Pankake, Ramalho, Mills, \& Simonsson (2014) indicated male mentors can be advantageous for female superintendents as a way to validate their capacity. The reality is there were few women in the position of superintendent and being accepted by the males in the position validated that I had the preparation and leadership skills necessary to be in the position.

Contrary to the notion that Latino males are dominating and adhere to machismo mannerisms, my experience was that Latinos were an important source of encouragement and support during my tenure as an administrator and as a superintendent. It was males who provided strength in words and actions when I encountered challenges. Latino males possess political and societal cultural capital in regard to navigating the superintendency and are often openly supported in the community. Their experience precedes females, and in my point of view their authority and actions were not questioned as were those of the females, and I think they knew this. I often found their shared experiences helpful and validating. Blout (1998) explained that in schools, students are aware of the power relationship between administrators and teachers. If students are accustomed to women as teachers and men as administrators, they form a schema in their minds about gender and power. This schema translates into society at large and how gender and power are related. In my opinion, it is not the fault of males, it is just a prevailing attitude in society at large that women need to accept and learn to navigate.

It was a former Latino superintendent who explained to me, it's not your fault your contract was not renewed, it's the nature of the position. This man was looked up to and respected in the Latinx and superintendent community. It was during this conversation he shared he had been a superintendent in different school districts, and he too had not had a contract renewed. He also shared how much more difficult it was for Latinas and how we often had to take positions far from home. He mentioned how poor Maria Lupe had to go way up north more than 400 miles from down south just to get her foot in the door and be a superintendent. For Latinas I have found this to be true, as a superintendent, I had to relocate twice. My first superintendency was 200 miles south of where I lived and the second superintendency was 200 miles north of where I lived. My children were adults, I aspired to be a superintendent, and my decisions were supported by my family and compadres.

In my career planning, I had a map of California and I drew the boundaries of how far I would travel for the position should an opportunity arise. Relocation or colocation is not uncommon in the superintendency or for higher-level district office positions. Males, females, minorities and whites all face the reality of going where the positions are, however for Latinas I think the challenges are greater. Having a career as a higher-level district administrator often requires being open to accepting a position far from home. As previously mentioned, there are only a thousand and some school districts in California and you need to go where the jobs are. The challenge is how far are you willing to go and how will you relocate or colocate.

\section{The Superintendency}

My first superintendency was in the southernmost region and county in California, the county was home to 16 school districts, and I was the only Latina superintendent. The school district was the largest in the county and had over 10,000 students, thirteen schools and over 400 teachers. In research conducted by Galiana, (2014), one of her participants accurately described the "position of the superintendent as lonely. The number of supporters and colleagues drops dramatically when you become the head of a large organization such as a school district". This sentiment accurately describes how I often felt. Exacerbating the situation was that I had relocated and was unfamiliar with the 
region and the ruralness. I felt different and reflecting on my tenure in the county I think there was some jealousy, or mistrust by the female Board member and by some members of the County office. It was a challenging time for many reasons. It was the first time I was in a superintendent position, it was a large $\mathrm{K}-12$ school district, and I think people did not understand or could not grasp that a Latina had the experience and knowledge to be the leader. After being in the position for almost a year my photo had still not been posted at the county office of Education. Next to the 15 superintendent photos was a blank space where my photo should have been. I never asked or questioned the county superintendent. After being in the district almost a year my administrative assistant, who was also a Latina, went to a county meeting and noticed that my picture was not on the superintendents' wall. When she returned from her meeting, she asked me if my picture had fallen from an earthquake and I told her no, that it had never been placed among my fellow superintendents. She immediately called the county and inquired as to why my photo was not on the superintendents' wall. She never told me what their response was, and I did not ask.

In the Galiana, (2014) study, it was stated, that to offset the isolation superintendents face and to cope with the additional pressures thrust upon them as educational leaders, the superintendents often turn to the support groups that have been there since the beginning, their families and in my case my comadres and compadres too. I would call them, meet with them when I was home, and I would always be warmly encouraged to hold my head high and to show them I could do this!

As a new superintendent, I was extremely fortunate to have an executive cabinet comprised of four accomplished Latinas. A couple of months into the position and due to a poorly functioning fiscal department I was able to hire a male recommended by friends from Southern California. He provided fiscal oversight and expertise, but more importantly, he provided friendship, support, and an understanding of female and Latina leadership through his previous experiences. I was different because I was an outsider and at times, I did not realize it, I would stand up to Board members and union leadership, I was confident in my knowledge and created a close relationship with my female cabinet members. They were smart, hard-working, knowledgeable and helped me to navigate the nuances of the community. What I was not prepared for and found the most challenging was dealing with a closed rural community. The area was closed off by the natural geography and newcomers were regarded with suspicion. I remember speaking to a Latino principal and he explained the community as such; "You know, they treat outsiders poorly, I have lived here for over 15 years, my wife has lived here her whole life, I have kids in the schools here and they still treat me like an outsider, it's just the way they are." This was a new experience for me, growing up in a largely suburban, urban area in a multi-ethnic community, there were educators and leaders of many ethnic backgrounds. As a principal and district office administrator, I had challenges, but I do not think they were as far on the spectrum as the community I was now a part of.

There were, however, many welcoming warm people in the community, the students and many staff members warmly welcomed me, some brought gifts or sent cards. Friends and colleagues sent flowers to congratulate me on becoming a "Superintendent". My parents and family were invited to a welcome reception hosted by the district. Some Board members attended as did local politicians including assemblymen, city government officials, parents, students and the administrative team who were all in attendance. The high school FFA students wore their regalia and invited me to visit them and their farm. Students and administrators and those Board members that attended remained supportive and friendly. The warmth and pride generated that evening provided much strength to get through the difficult days I was to encounter. 
My introduction to the position was being presented with challenges that needed immediate attention. The district had tremendous fiscal, personnel and curriculum challenges. The district was being investigated for mismanaging millions of dollars from state and federal sources, had a budget deficit of over millions of dollars, and Board members had lawsuits against each other, these were among the most demanding issues. In comparison, there were additional minor challenges, that I am sure would have been major issues in other districts. The primary and continuing challenge came from two board members who were vicious and had self-serving interests. When they became aware that I was not willing to compromise my ethics for their gain, our relationship became and remained adversarial. Unfortunately, the Assistant Superintendents and administrative staff also suffered from their negative behavior.

I was grateful and fortunate to have a supportive site and district office administrative team consisting of principals, assistant principals, directors and assistant superintendents. The support of the administrative team and three Board members who were also adversaries of the other two Board members made the position at times enjoyable and a great learning experience. We shared a comradery that we were all in this together. Most of the team were Latinx or were from the area and had acculturated to the Latinx culture of the community. Two of the most supportive Board members were Latinos who were administrators in neighboring districts. They understood the challenges of being a Latino leader in the county and the challenges that needed attention in the school district. We would often meet for coffee or lunch and discuss agenda items and strategies as to how to move the district in a positive forward motion. The Board president was also supportive. He and I would meet once a week to discuss Board business and concerns from the community. Looking back on those meetings, I think it was a way for them to show support, and I believe they wanted to have a positive influence on the students and their community.

\section{Leading Under Pressure}

The greatest challenge of my tenure as superintendent and my career, in general, was providing leadership, knowledge and insight regarding the interruption of educational programs and the district's fiscal and physical recovery following a 7.2 earthquake that resulted in school closures of 17 and 21 days and partial permanent closure of one school for the remainder of the year. The situation was challenging due to the extensive damage that occurred from the initial quake, which thank God occurred on a weekend, and from the thousands of aftershocks over magnitude 3.5. The numerous aftershocks lasted for months and continued to damage the infrastructure, including a broken gas line during the school day that resulted in some of the schools being evacuated.

On the evening of the quake, I toured the most damaged school site with the school's principal and the district's Maintenance Operations and Transportation director. It was horrifying to see outside hallway ceilings that had fallen and sheered doorknobs off. There were water mains broken and electrical outlets that were getting wet. I was contacted by the local police and fire captain asking if the high school gym could be used as an evacuation center, only to find out the building had been red-tagged and declared unsafe to enter.

The following morning, I can remember my administrative assistant and I discussing the necessary steps for calling an emergency meeting in order to assess the damages and to acquire the resources to move forward. We met in the district office where we could not sit at our desks due to debris, broken windows, and bookshelves that had fallen over. The building had a long tiled hallway that now looked like the back of a dragon with missing tiles and ripples in the concrete. Due to our communication and internet services and systems being inoperable my assistant had to travel to the next town to call the attorney who provided the proper instructions for calling and posting an emergency Board meeting. I later learned I was one of only a few superintendents who had to call an emergency meeting due to a real emergency. 
The district did not regain internet or phone service for several days, and cell phone coverage was intermittent. The district office was deemed unsafe, as was most of the district's facilities. The entire city was affected, and damages were assessed and continued to be reassessed daily due to the constant aftershocks. It was necessary to have meetings for essential staff members, so I posted signs and began meetings with warnings such as," this building has not been cleared as safe to enter, so you may leave if you'd like." The entire city was affected and those invited to meetings came and assisted in the recovery efforts. We worked what seemed to be 24 hours a day, seven days a week. As new damages and situations occurred I was often called as early 4:30 AM and notified of damages or of visitors from news teams, television stations, the governor's office or to inform me State officials were coming to town and I needed to prepare to meet with them coordinate tours of the damage sites. The Director and representatives from FEMA (Federal Emergency Management Agency) and CalEMA (California Emergency Management Agency) and various other state and local agencies spent days touring and viewing the damage. Many later returned to welcome students when the schools reopened. We were fortunate that a representative from CalEMA was assigned to the district to assist with coordination, recovery efforts and to assist with providing information to state and federal agencies. The representative provided support in the form of suggestions and resources for the district's recovery efforts, and most importantly he provided me with disaster mentoring and friendship.

What I learned from the experience is that there is nothing routine regarding the superintendent position and that all challenges can and must be addressed. Accepting assistance and including others in the tough discussions can be very beneficial. It's also a good idea to have a suit or dress jacket with you at all times, just in case the governor or television stations show up.

\section{It's Important to Celebrate Success}

Celebrations, acknowledging others and paying tribute are important aspects of leadership. In the Latinx community celebrations are an important cultural attribute that brings people together and recognizes community efforts.

When the schools reopened, we celebrated with a big fiesta in the park, each school hosted a booth and the local high school students performed. The city set up a stage and the Border Patrol provided lighting. So many parents and grandparents thanked me for keeping their children and grandchildren home and safe and for thinking of their well-being, I was confident and supported in the decisions I had made. FEMA honored me at a Board meeting and stated that through my leadership and actions I had saved the district millions of dollars. State officials also addressed the Board on my behalf. The Governor had declared the incident a state of emergency that provided emergency assistance for personnel, and recovery recommendations, including the California Department of State Architect (DSA) engineers to assess, reassess and assist with recovery efforts and for expediting much need funding for disaster relief.

I was invited to speak at the earthquake engineers' annual conference and complemented by DSA for my leadership regarding the disaster and for supervising the facilities rebuilding efforts. Despite our best efforts my decisions and actions remained continuously questioned by one of the Board members, who incited community members and the County superintendent who refused to assist in the district's recovery efforts for lost days of attendance.

As an administrative team and executive cabinet, we remained united and confident in the decisions we made. We were dealing with a disaster and simultaneously addressing the day to day duties of leading a school district. After one contentious Board meeting I can remember one of the Assistant superintendents, thanking me for treating them with respect and for allowing them to make decisions regarding their departments, she stated it was the first time 
she felt respected and that I provided strong leadership that made her a stronger more confident leader. These are the important conversation and to me those that were the most significant. I was proud that I was able to foster confidence in the leadership of the administrators and especially with the Latinas I worked with. Board meetings often ended as late as midnight and sometimes until 1:00 AM. Instead of saying we were tired and going home to sleep, the executive cabinet members and I would go to the all-night Denny's for coffee, tea and dessert. We would laugh and encourage each other, each taking a turn to acknowledge the hard work being completed. The resilience of the Latino community is amazing, despite all the challenges, we celebrated our unity.

The executive cabinet suggested I host a Christmas party at my house, and I agreed. The administrative team organized a potluck with tamales, desserts and amazing foods. The head of maintenance brought a karaoke machine and one of the principals brought his accordion, we sang, we danced, and we celebrated each other after it was over, they all pitched in to clean up and pack up and get my house back in order. We knew it was most likely the end of my tenure in the district and we knew that challenges remained. The site leaders drafted a letter of support for me which was presented to the Board and they thanked me for my leadership.

The stress of the earthquake recovery, addressing the budget and personnel issues, the results of the November elections and the new school year changed everything. Four of the five Board members left; two who decided not to run again, because they had made a pact when they were first elected, that if the district was not in a better place than when they began their boardsmanship they would not run again; one member who decided to move out of the district and who said he could not take the stress, which interestingly in my opinion he created; and one Board member did not get reelected. The challenges of the district would have been insurmountable for anyone, but for me, I considered it as a personal failure and questioned my abilities, was it because I was a woman, was it because I was a Latina? After all my efforts, I was tremendously disappointed when I left the district. In retrospect, could I have made different decisions, maybe a few. However, in the aftermath of a 7.2 earthquake and with the continued aftershocks, someone had to make decisions and I am confident I would make the same ones again.

The challenges of my first superintendency provided some of the best learning experiences for me as a Latina and superintendents in general. An important relationship most superintendents have is with their district's attorneys. I was fortunate to work with outstanding gentlemen. Two that stand out were an African American and a Latino who provided what seemed to be 24-hour service. Their assistance with the difficult board and the earthquake recovery was appreciated. They also provided "mentoring" and seemed to have a genuine interest in my success. An example of this is when one of the district's Latino attorneys and I were having a heated discussion regarding feuding Board members and out of frustration I said to him, "I am an educator, not a politician", and he replied, "maybe that is your problem". As odd as it may sound, I had not realized this important factor, which for me was a personal and difficult concept, one that in reflection I never fully embraced. It was not that I could not be politically astute, or tough, but dealing with those who did not consider the needs of students first was an uncompromising moral attribute of mine. I could not or would not place the needs of children or a student as a secondary consideration. I don't think that is what he was attempting to have me realize, I think he cared about my leadership and wanted to ensure I expanded my point of view.

My second tenure as a superintendent was in a small rural district that had an enrollment of 2,500 PK-12th grade students in six schools. I was once again a unique superintendent. I was the district's first Latina superintendent and of 43 superintendents in the county the only Latina. The district was located in a small town that had a population of 10,000. Everyone in the community seemed to get along and most were kind and respectful. 
It was in this district that I received some thoughtful "mentoring". Mentoring per se was different for me in the context of Latino cultural responsibilities and caring for each other. In the context of Latinas who encounter challenges due to the limited number of role models who look like them or share their culture, the concept of Latinx style mentoring or what I refer to as compadrasco, Latinx mentoring, is embedded in our cultural history. One of the most helpful actions was by a Latino Board member who welcomed me to the district. He took me on a tour of the city, showed me where the markets and shopping centers were. He also shared areas to avoid, while we were touring, we discussed what was needed in the community and what he hoped for the school district. He was also astute enough to know I was driving back and forth to Los Angeles from the Central Valley, a comfortable three-hour drive passing through beautiful countryside. However, he warned me to stay on the highway and mentioned a few places off the freeway that I should probably not visit. In my tenure as a superintendent, one of the most beneficial and treasured relationships was with the only female Board member who also was a Latina, she would visit my office, call and bring me delicious homemade persimmons cookies, we would speak to one another not only about policy and politics but about family and challenges that I was addressing. She would invite me to attend school and community meetings and events with her. The invitations provided additional opportunities to be seen after hours at the school sites and in the community. After leaving the district she has become a trusted friend and confidant.

"Putting Children, Students First" has always been my motto. It has served me well and kept me aligned with my moral compass. It may seem odd to consider this, however as previously mentioned the Superintendency is a political position as well as an educator position. It's amusing now, but it wasn't so fun when I was going through a difficult time with a high school principal leading the charge to discredit me as the superintendent and as a person. I had initiated an investigation of the football coach and recommend a reprimand for his abusive behavior towards one of the students. It was a situation I do not regret addressing. As an assistant superintendent, I worked for a superintendent who chose to look the other way when a complaint was filed against a winning CIF football coach, who I helped investigate and verified, that he had physically and in anger inappropriately disciplined a student. When the information was shared with the Board one of them was so angry, he stated "this isn't the first time", and still not much was done in the way of disciplining the coach following the recommendation of, little to no action needed, by the superintendent. When I was confronted with a similar situation as superintendent, I felt compelled to recommend appropriate action including a reprimand and the Board agreed. Unfortunately, it only angered the high school principal and he increased his attacks. During these difficult times, I was at an out of district meeting and a fellow Latino (former) superintendent offered his consejo (advice); "Mija6, what were you thinking to take on a high school CIF winning football coach", he grinned and told me I did the right thing for the right reasons and we laughed. It is difficult to be political and it is even more difficult to follow your moral compass, but what I can say is, "I would make the same decision to address the issues I faced in the same way, because students and safety were always primary considerations. I am not unique in placing the needs of children first or of being compassionate, I think this is a strength of females and for Latinas in particular.

In a research study of female superintendents MacArthur (2010) quoted one of her participants as stating, “Be who you are, and know at the end of the day you did everything you could to help kids." MacArthur further went on to advise women aspiring to the superintendency to maintain their integrity, courage and passion. In a similar study by Guzman (2012) the first of her key findings was that female superintendents rated a "strong determination to always put the best interest of children first."

6 Mija-The literal translation in English is daughter, however, mija is also used as a term of endearment or care for a person 


\section{Grace, Sanity and Poise}

As a superintendent when I was being attacked by unhappy personnel, I was often featured on the local radio station. Sometimes I would be provided with the question in advance and often times I was not. The radio programs were usually taped in the early mornings, the first broadcast was live and unedited. The taping provided for listeners in the afternoon. The broadcasters were always polite and understood that the negative information being circulated was more often than not false and or inaccurate. In the final weeks of my tenure as superintendent, I was at a county meeting, when a fellow female superintendent said to me, I listen to you on the radio and you are always poised and say positive things about your Board and the district. "I want you to know, you have been good for the community and for the county as well".

Sometimes you do not realize who is listening and how you sound, for me remaining positive and complementary to the community was important. There were so many positive members in the community and there were those who said they were sorry to see me being attacked and were sorry that they did not vocalize their support. It was always an honor and a privilege to be a superintendent. I understood the challenges, the importance and the responsibility of the position. I have no regrets as to the decisions I made. I remain grateful for being a member of a very elite group and I cherish the lasting friendships and leadership I was able to maintain. In a study by T. Brunner, she sums up the importance of female superintendents with the quote, "Women who rise to the pinnacle of their careers and achieve top educational positions are a national minority" (pg.9). This quote has so much more meaning for those of us who also happen to be Latinas.

\section{Final Thoughts}

As a former high-level district administrator, I share the sentiment, it's lonely being at the top. For Latinas, I think feelings of insecurity and isolation are greater than for others. Not only are Latina superintendents elite administrators, but they are also different than most of the administrators around them. They may have more in common with the classified staff than with the certified and administrative staff. They may also be one of the small number of females among the administrative ranks.

Self-care is an important practice that is difficult to make time for, but it is important. For me, faith was and remains an important practice. As a new administrator, I would drive around town to gain an understanding of where the students and families lived. The practice also allowed me to find out where I could get lunch, visit the community and where I could go for a quick prayer or attend afternoon mass on the tough days

Ken Magdaleno, Educator and developer of Latino administrative mentoring programs have stated:

The dominant White culture in the State of California presently controls the condition of educational leadership and its decision-making power. If the state of education and its educational leadership are going to improve for Latino leaders, then those in power must be persuaded of the benefits of inclusion. However, until such change takes place, Latinos themselves must continue to develop a strong network of influential decision-makers sensitive to the needs of Latino leadership. Magdaleno, K.R. (2011) Mentoring Latina/o Leaders in Cooper, B. S., and Conley, S., Keeping and Improving Today's School Leaders. 
The advancement of Latinas in educational administration cannot be attained on their own. It is the responsibility of our communities and institutions to promote equitable thinking and access to the necessary opportunities required for advancement and success in the superintendency.

Until that occurs promoting Latinas will require collective efforts and acknowledging our responsibility to take care of ourselves and to promote those who share our similar attributes.

\section{A Link to the Past and a Step to the Future}

The Latino culture has many attributes for fostering, improving and maintaining Latina leadership and traditional values. The concept of Bien Educado7, being respectful, kind, and caring and the concept of Respeto (respect), for human dignity and values is embodied in the cultural importance of familia that exceeds the boundaries of the nuclear family and is a common practice that embodies a collective caring for extended non-nuclear family members. Support, loyalty, reciprocity, and solidarity are traits representative of this ideal. In my experience the Latinas and Latinos I refer to as comadres and compadres were conscious of the obstacles and issues that I encountered. It was through their continued support, encouragement and consejos (words of advice) that I was able to persevere and develop as an educational leader. Recognizing and embracing to what I have referred to as comadrasco or compadrasco is a Latinx administrative cultural attribute and value that can sustain and advance our goals.

It was a Latino who encouraged me to get my doctorate and to later become a superintendent, he has been a mentor and friend for my entire administrative career, I consider him more than a friend he is a compadre, he knows my family and celebrates with us. It was a Latino superintendent who was the first to provide encouragement for me to pursue the superintendency. More than 10 years before I became a superintendent this wonderful Latino told me, one day I would be a superintendent. Many years later we met again, and I reminded him that he was the first person to tell me I could do the job and I did. When he asked how I was doing I told him about the CIF football coach, and he was the one who told me the Mija what were you thinking story. I thanked him and gave him a hug, and he told me I was going to be ok, and he was right!

I have been fortunate to develop lasting relationships with comadres and compadres when I began my educational career as a bilingual teacher. The relationships and consejos they have provided over the years are the real secrets to my success. As a Latina high-level administrator, you need la familia to gain parity and to continue to grow. Latinx mentorship is important to give and to receive. Cultivating, accepting and maintaining Latinx cultural capital provides a familial sense of mentorship that is important and can help when ascending to the superintendency,

Have I felt discrimination, have I been treated unfairly, have I had to face challenges others may not have had to? My response is, "yes, but so what". I was one of few and I am proud to say I was a superintendent in California, and I made a difference. Consejos, dulces (words of wisdom and sweet treats) for the next generation of Latinas: First and foremost, know your worth and don't be afraid to exert your power. Let your knowledge shine and celebrate the resilience and strength of your cultura (culture) and familia (family). In the MacArthur (2010) study the advice shared by one of her female superintendent participates was for women applying to the superintendency, you must develop a thick skin, and I agree. As a Latina principal, I can remember one of the teachers telling me my skin must be as thick as that of an orange, and I replied it's more like the rind of a watermelon. Another bit of advice from the MacArthur (2010) study, "Be sure you are mentally and emotionally prepared." I would also add be healthy and stay healthy too.

$7 \quad$ Bien Educado literally translated into English is well educated. However, the translation used in this manuscript is not the literal but cultural use of the term. The term encompasses the nuances of the cultural translation. 
Mentors, consejos, friendships and opportunities have assisted me throughout my career as a high and elite level administrator. They may not be in the traditional sense, but support is there and it's up to the individual to seek and take advantage of them. Remain true to yourself and don't be afraid to take risks!

\section{Final Thoughts}

As a group, the Latinx population needs to not only continue but urgently surpass current educational strides. High school dropout and completion rates among Latinx children are decreasing however, the rates still lag far behind those of the White population. As of 2014, only $15 \%$ of Hispanics were reported to have attained a Bachelor's degree as compared to $41 \%$ for Whites. (Krogstad, 2016) Teacher certification in California currently requires a Bachelor's degree and an additional post-degree credential that may take one to two additional years to attain. Administrators in California typically have a Master's degree in administration and they must also acquire an administrative credential that often requires additional school usually lasting from 18-24 months. Many superintendents in California have a doctorate degree that may take 3-6 years to attain. The study of MacArthur (2010) indicated women without doctorates face difficulties rising through the administrative ranks. As a cultural group, the Latinx population must not only attain but surpass educational parity with Whites, in order to provide role models, and culturally and linguistically sensitive practitioners.

There is a need for additional research regarding the small minority of Latinx administrators, high-level district and elite administrators. For the purpose of this study, reference was made to what works in the classroom and how teachers can address the needs of Latinx students. These references have been applied to administration and leadership due to the belief by the author that in general administrators have years of experience as teachers and often carry those traits with them to their administrative positions.

Research by Hollins (2012) indicated, the teacher community at a particular school site has a powerful influence on learning to teach, teaching practices, ideology, and that personal and professional identity are powerful influences on opportunities for learning and for learning outcomes. The more recent research of Hollins is reflective of the early research by Moll (1988) that indicated the need for culturally responsive practices in our schools. I would add as school leaders we need to practice being lifelong learners to better serve our students and their communities.

In the Learning Policy Institute Report: Learning to Lead: Understanding California's Learning System for School and District Leaders the researchers introduce their study with "Improving student achievement in California requires strong school and district leadership" (Sutcher, Podolsky, Kini \& Shields, 2018 pg.1). The study indicated the ongoing need for professional development for principals and administrators in general. The research conducted with principals illustrated the need for principals requesting opportunities "to be prepared to lead for deeper learning and support of the whole child." And the need for supporting principals working in underserved communities is key to better addressing the state's persistent achievement gaps. The study defined one of the competencies needed was "supporting students from diverse ethnic, racial, linguistic and cultural backgrounds." Perhaps the need to address the whole child and those that are culturally and linguistically different can be improved by advancing and encouraging bilingual/bicultural teachers to the principalship and to high-level and elite-level administrative positions.

The Sutcher, Podolsky, Kini, and Shields (2018) report included professional learnings of superintendents. One of the superintendents in the report stated, "What is unique is that at the district level the superintendent and team provides the learning for principals and provides learning for directors and provides learning for teachers and classified 
staff and so forth." (pg.10) The urgency of this statement once again can be attributed to the lack of cultural and linguistic leadership, calling for an increase in the number of high-level leaders that share similar linguistic and cultural traits similar to the students in our schools. One of the final recommendations of the report is to "Build a Pipeline-To build a robust pipeline of qualified and committed school principals through service scholarships and residency programs for school leaders." (Sutcher, Podolsky, Kini \& Shields, 2018 pg.11). If this pipeline were to be equitably developed, a cadre of many Latinx administrators could be leading California schools in the near future and change the racial, linguistic and gender dynamics of educational leadership. 


\section{References}

Balderama, F. E., \& Rodriguez, R. (2006). The family La Vida. In Decade of betrayal Mexican Repatriation in the 1930s Revised Edition, Albuquerque, New Mexico: University of New Mexico Press.

Blout, J. M. (1998). Destined to rule the schools 1873-1995 (1st Ed.). Albany, NY: State University of New York.

Brunner, T. (2018). A study of advancement: Female superintendents breaking the glass ceiling (13811718) (Unpublished doctoral dissertation).

CalEdFacts 2019. Fingertip Facts on Education in California - CalEdFacts. Retrieved November 15, 2019, from https://www.cde.ca.gov/ds/sd/cb/ceffingertipfacts.asp

California Department of Education. (2018). California Department of Education data quest. Retrieved from https://dq.cde.ca.gov/dataquest/Staff/StaffByEth.aspx?cLevel=State\&cYear=2017-18\&c Choice $=$ StateNum\&cType $=$ A\&cGender $=$ B\&Submit $=1$

Cano, M. (2019). The underrepresentation of Latinas in the Central Valley superintendency: A qualitative study of barriers faced and strategies used by successful Latinas (Unpublished doctoral dissertation). California State University Fresno, Fresno, CA.

California Department of Education/ DataQuest. (2019). Certificated staff by ethnicity. Retrieved November 15, 2019, from https://dq.cde.ca.gov/dataquest/Staff/StaffByEth.aspx?cLevel=State\&c Year $=2018-19 \&$ cChoice $=$ StateNum\&cType $=$ A\&cGender $=$ B\&Submit $=1$

Cejas, J. (2013). Barriers, resiliency, leadership, mentoring and networking: Factors influencing the ascension of Latino/as to the superintendency of public schools in California.

California State University, Sacramento: Dissertation.

Cooper, B. S., \& Conley, S. (2011). Mentoring Latina/o Leaders. In Keeping and Improving Today's School Leaders: Retaining and Sustaining the Best (1st ed., pp. 83-100). Plymouth, United Kingdom: Rowman and Littlefield.

Denzin, N. K., \& Lincoln, Y. S. (2011). The SAGE Handbook of Qualitative Research. Thousand Oaks, CA: SAGE.

California Department of Education Enrollment by Ethnicity and Grade. (2019). Retrieved September 5, 2019, from https://dq.cde.ca.gov/dataquest/dqcensus/EnrEthGrd.aspx?cds=00\&agglevel=state\&year=2018-19

Campbell-Jones, F. \& Avelar-Lasalle, R. (2000). African American and Hispanic superintendents: Factors for success. (ERIC Document Reproduction Service No. ED443931).

Galiana, A. A. (2014). The Hispanic Superintendent. Rutgers Graduate School of Education: Dissertation.

Guzman, A. (2012). California women and the strategies utilized on the path to the superintendency (3535788) (Doctoral dissertation). Retrieved from ProQuest Dissertations and Theses Global: The Humanities and Social Sciences Collection. (3535788) 
Hollins, E. R. (2012). Learning to teach in urban schools. The transition from Preparation to practice. New York and London: Routledge.

Krogstad, J. M. (2016, June 28). 5 Facts about Latinos and education. Retrieved from http://www.pewresearxh.org/fact-tank/2016/07/28/5-facts-about-latinos-and-educatio/

Lindsey, R. B., \& Lindsey, D. B. (2016). Build cultural proficiency to ensure equity. Learning Forward.Org, 37(1), 50-56. Retrieved from www.learning forward.org

MacArthur, T. (2010). Women and the superintendency: Characteristics and barriers encountered by female superintendents in California (Doctoral dissertation). Retrieved from ProQuest Dissertations and Theses database.

Magno, H. (2014, April 12). Dale Dale Dale [Video file]. Retrieved from http://youtu.be/liBBCD15e5Y

Méndez, M. (2013). Autoethnography as a research method: Advantages, limitations and criticisms. Colombian Applied Linguistics Journal, 15(2), 279-287.

Moll, L. C. (1988). Some Key Issues in Teaching Latino Students. Language Arts, 65(5), 465-472.

Muñoz, A. J., Pankake, A., Ramalho, E. M., Mills, S., \& Simonsson, M. (2014). A study of female central office administrators and their aspirations to the superintendency. Educational Management Administration and Leadership, 42(5), 764-784.

Skrla, L (2001). Sexism, silence and solutions: Women superintendents speak up and speak out. Educational Administration Quarterly, 6(1), 44-75.

Sutcher, L., Podolsky, A., Kini, T., \& Shields, P. M. (2018). Learning to lead: Understanding California's learning system for school district leaders. Retrieved from Learning Policy Institute website: https://learningpolicyinstitute.org/product/california-learning-systems

Valencia, R. R., \& Black, M. S. (2002). Mexican Americans don't value education! On the basis of the myth, mythmaking, and debunking. Journal of Latinos and Education, 1(2), 81-103.

Whitehead, J., \& Lomax, P. (1987). Action research and the politics of educational knowledge. British Educational Research Journal, 13(2), 175-190 